\section{Psicologia Escolar \\ e Educacional}

ARTIGO

DOI: http://dx.doi.org/10.1590/2175-35392021226497

Localizador - e226497

\title{
CONTRIBUIÇÕES DA PSICOLOGIA ESCOLAR PARA FORMAÇÃO DE PROFESSORES EM UNIVERSIDADES PRIVADAS PAULISTAS
}

\begin{abstract}
Ana Karina Amorim Checchia ${ }^{1 ; 2} \mathbb{D}$; Sandra Sawaya ${ }^{2} \mathbb{D}$
RESUMO

As disciplinas de Psicologia ministradas na Pedagogia centram-se, tradicionalmente, no desenvolvimento humano e na aprendizagem, enquanto o cotidiano escolar é pouco analisado; tal centralidade vem sendo problematizada pelo movimento crítico no campo da Psicologia Escolar. Fundamentado nesta perspectiva, este artigo objetiva explicitar contribuições que disciplinas de Psicologia, lecionadas em cursos de Pedagogia em Universidades privadas paulistas, podem propiciar na formação inicial de professores, para a compreensão do processo de escolarização, a partir de subsídios oferecidos pela Psicologia Escolar. Para tanto, foram realizadas entrevistas semiestruturadas com quatro coordenadores de cursos de Pedagogia e sete docentes destas disciplinas. Identificou-se a busca dos entrevistados por inserir nesta disciplina a discussão de temas da Psicologia Escolar, como fracasso escolar, medicalização da Educação, estigmatização nas relações escolares e o cotidiano escolar, que não constam nos planos de ensino. Evidenciou-se, portanto, a necessidade de abordar questões do campo da Psicologia Escolar como conteúdo formativo dos educadores.

Palavras-chave: formação de professores; pedagogia; psicologia escolar
\end{abstract}

\section{Contributions of School Psychology in the teacher graduation course in private universities in São Paulo}

\begin{abstract}
The Psychology disciplines taught in Pedagogy are traditionally centered on human development and learning, while everyday school life is little analyzed; such centrality has been questioned by the critical movement in the field of School Psychology. Based on this perspective, this article aims to explain contributions that Psychology disciplines, taught in Pedagogy courses in private universities in São Paulo, can provide in the initial teacher training, for the understanding of the schooling process, based on subsidies offered by School Psychology. For this purpose, semistructured interviews were carried out with four coordinators of Pedagogy courses and seven professors of these disciplines. It was identified the interviewees' search for inserting in this discipline the discussion of themes of School Psychology, such as school failure, medicalization of Education, stigmatization in school relations and daily school life, which are not included in the teaching plans. Therefore, the need to address issues in the field of School Psychology as a formative content for educators was evident.
\end{abstract}

Keywords: teacher education; pedagogy; school psychology

\section{Contribuciones de la Psicología Escolar para formación de profesores en universidades privadas paulistas}

\section{RESUMEN}

Las asignaturas de Psicología ofrecidas en la Pedagogía se centran, tradicionalmente, e el desarrollo humano y en el aprendizaje, pero el cotidiano escolar es poco analizado; tal centralidad sigue siendo problematizada por el movimiento crítico en el campo de la Psicología Escolar. Fundamentado en esta perspectiva, este artículo tiene por objetivo explicitar contribuciones que asignaturas de Psicología, ofrecidas en cursos de Pedagogía en Universidades privadas paulistas, pueden propiciar en la formación inicial de profesores, para la comprensión del proceso de escolarización, a partir de subsidios ofrecidos por la Psicología Escolar. Para tanto, se realizaron entrevistas semiestructuradas con cuatro coordinadores de cursos de Pedagogía y siete docentes de estas asignaturas. Se identificó la búsqueda de los entrevistados por inserir en esta asignatura la discusión de temas de la Psicología Escolar, como fracaso escolar, medicalización de la Educación, estigmatización en las relaciones escolares y el cotidiano escolar, que no están presentes en los planes de enseñanza. Se evidenció, por lo tanto, la necesidad de abordar cuestiones del campo de la Psicología Escolar como contenido formativo de los educadores.

Palabras clave: formación de profesores; pedagogía; psicología escolar

\footnotetext{
${ }^{1}$ Universidade Paulista (UNIP) e Universidade de São Paulo (USP) - São Paulo - SP - Brasil; anakarina.ak.ac@gmail.com

2 Universidade de São Paulo (USP) - São Paulo - SP - Brasil; smsawaya@usp.br
} 


\section{INTRODUÇÃO}

As disciplinas de Psicologia ministradas nos cursos de Pedagogia, tradicionalmente apresentam como foco principal a exposição de teorizações psicológicas sobre o desenvolvimento humano e a aprendizagem, de modo a centrar a análise de questões na interface Psicologia e Educação no âmbito individual, enquanto impera o distanciamento entre o conteúdo nelas ministrado e a realidade escolar (Paini, 2006; Guerra, 2003; Gatti, 2009, Gatti \& Nunes, 2009).

Esta centralidade no indivíduo, subjacente a tais disciplinas, é expressão do modo como a Psicologia se insere, historicamente, nos cursos de Pedagogia, que segundo Antunes (2003) e Libâneo (2012), é marcado pelo psicologismo (ou psicologização) da Educação, compreendido como o reducionismo de questões que configuram o contexto educacional à dimensão psicológica ou individual, alicerçado em um "enfoque estritamente psicológico, que ignora o efeito das condições sociais e políticas sobre o comportamento, tornando subjetivos os problemas gerados pela estrutura social e econômica" (Libâneo, 2012, p. 156).

Nesse sentido, ao contextualizar o ensino da Psicologia da Educação na formação de professores, Libâneo afirma que esse foi se reduzindo "à descrição de teorias sobre os estágios do desenvolvimento infantil ou às técnicas de diagnósticos e tratamento das dificuldades de aprendizagem e distúrbios emocionais" (2012, p. 154), centrando sua análise no indivíduo abstrato, sem atentar para a constituição social e histórica dos fenômenos educativos. Diante de tal reducionismo, a análise da instituição escolar, do cotidiano escolar e da complexidade de elementos implicados no processo de escolarização recorrentemente encontra-se ausente dos planos de ensino de disciplinas de Psicologia na Pedagogia, conforme Pereira, Almeida e Azzi (2002), Gatti e Nunes (2009) e Larocca (2000) evidenciam em suas pesquisas.

O questionamento do reducionismo de questões sociais e educacionais ao âmbito individual, bem como a relevância de analisar o cotidiano escolar e o processo de escolarização em sua complexidade vêm sendo enfatizados ao longo do movimento crítico no campo da Psicologia Escolar. Fundamentada no materialismo histórico, esta perspectiva crítica explicita as raízes dos fenômenos estudados na interface Psicologia e Educação, em oposição à sua naturalização, de modo a atentar para elementos sociais, políticos, institucionais e relacionais implicados no processo de escolarização, situando-o na conjuntura social vigente regida pelos ditames do modo de produção capitalista (Patto, 1997, 2015).

Com base, portanto, em uma perspectiva crítica, o foco de análise dos fenômenos nessa interface desloca-se da centralidade do indivíduo abstrato para a refle- xão sobre o processo de escolarização e as relações intersubjetivas que constituem o cotidiano escolar, concebendo-se o sujeito como um ser histórico, produto e produtor das relações sociais e da sociedade (Souza, 2010). Nesse sentido, as questões escolares são investigadas no contexto educacional brasileiro, analisando-se o modo como essas condições objetivas se concretizam no cotidiano escolar e suas implicações para a escolarização, bem como a especificidade da vida escolar desse sujeito (Patto, 1997).

Considerando, portanto, a crítica ao psicologismo da Educação na formação de professores e ao reducionismo de questões sociais ao âmbito individual no campo da Psicologia Escolar, realizamos uma pesquisa de Pós-Doutorado pela Faculdade de Educação da USP, em que nos dedicamos à análise das seguintes indagações: de que modo reflexões realizadas no campo da Psicologia Escolar, que apresentam como foco de análise o processo de escolarização, estão presentes nas ementas e nos relatos de docentes que ministram disciplinas de Psicologia em cursos de Pedagogia em Universidades privadas no Estado de São Paulo? Que contribuições essas disciplinas oferecem atualmente para a formação de professores, levando em conta as críticas que vêm sendo proferidas ao reducionismo de fenômenos educativos ao âmbito individual? Partindo dessas questões norteadoras, nossa pesquisa apresentou como objetivo a investigação de contribuições que as disciplinas de Psicologia, ministradas em cursos de Pedagogia em Universidades privadas paulistas, podem propiciar na formação inicial de professores, para a compreensão do processo de escolarização, a partir de subsídios oferecidos pela Psicologia Escolar.

Buscou-se, portanto, por meio dessa pesquisa, propiciar uma reflexão sobre o modo como o conhecimento produzido nos últimos anos, no campo da Psicologia Escolar, como expressão dessa mudança de foco do movimento crítico, tem sido veiculado aos estudantes de Pedagogia.

Por fim, deve-se ressaltar que a importância de atentar para os cursos de Pedagogia em Universidades privadas decorre tanto do grande contingente de professores exercendo a atividade docente nas escolas, que são egressos desses cursos em Instituições de Ensino Superior (IES) privadas (Almeida, Pimenta, \& Fusari, 2016), quanto da significativa prevalência de IES privadas neste país - que possui 2.111 instituições privadas em contraposição a 296 públicas (sendo 510 privadas e 99 públicas no estado de São Paulo) (INEP, 2017) responsáveis, portanto, pela formação da maioria dos egressos da Pedagogia que atuam nas escolas públicas.

\section{MÉTODO}

Para tal investigação, foi realizada uma pesquisa qualitativa (Denzin \& Lincoln, 2006), baseada no estudo de 
caso (André, 1995), em quatro Universidades privadas da cidade de São Paulo, dentre as quais encontram-se tanto instituições particulares (em sentido estrito: com fins lucrativos), quanto comunitárias e filantrópicas (ou seja, beneficentes: laicas e confessionais).

Os participantes da pesquisa, referidos neste artigo por nomes fictícios, foram quatro coordenadores de cursos de Pedagogia e sete docentes de disciplinas de Psicologia desses cursos. Como procedimentos dessa investigação, foram realizadas: a) entrevistas individuais com os participantes da pesquisa, totalizando onze entrevistas, utilizando-se como instrumentos roteiros de questões semiestruturadas (Queiroz, 1983); b) análise de documentos, que envolveu o processo de leitura e análise de ementas e planos de ensino de disciplinas nessa interface, ministradas nos cursos de Pedagogia, bem como da matriz curricular desses cursos. Buscou-se investigar nos discursos dos entrevistados e nos documentos analisados a estrutura dos cursos, o conteúdo ministrado e a presença de conhecimentos proferidos no campo da Psicologia Escolar na formação de professores.

Por fim, a análise de dados foi realizada com base na proposta de "análise de prosa" (André, 1983), por meio da qual temas centrais foram identificados a partir da leitura do material investigado e analisados à luz da perspectiva crítica em Psicologia Escolar, que fundamentou teoricamente essa pesquisa.

\section{RESULTADOS E DISCUSSÃO}

Foi possível identificar uma forte incidência de disciplinas de Psicologia nos cursos de Pedagogia pesquisados. Dentre esses cursos, dois apresentam três anos de duração enquanto dois são realizados em quatro anos e os quatro cursos contêm em sua matriz curricular disciplinas de Psicologia, com variações em sua quantidade e distribuição ao longo dos cursos. Em um dos cursos com quatro anos de duração, são ministradas 3 disciplinas de Psicologia obrigatórias (do 10 ao 3ำ período do curso), enquanto no outro, além de 5 obrigatórias (entre o 1 은 e o 70 períodos), também são oferecidas 3 disciplinas eletivas. Em relação aos cursos com duração de três anos, em um são oferecidas 5 disciplinas (do 10 ao 50 período) e, no outro, 3 (entre o 10 e o 50), sendo todas obrigatórias nesses dois cursos. Nos quatro cursos, tais disciplinas são oferecidas sem a realização de estágios.

Tal incidência é confirmada, não apenas pela presença dessas disciplinas em metade dos semestres que compõem um dos cursos e em mais da metade de outros dois cursos, chegando a abranger desde o primeiro ao penúltimo período no curso com maior notoriedade nessa ênfase atribuída à Psicologia na Pedagogia, mas também pelo fato evidenciado na análise das ementas curriculares dos cursos de Psicologia, de que ela permanece sendo um dos pilares para a fundamentação teórica que embasa a formação de professores desses cursos. Francisco, coordenador de um dos cursos pesquisados, explicita esse fato ao afirmar que a Psicologia consiste na base de sustentação teórica para a formação do pedagogo.

Historicamente considerada como um dos Fundamentos da Educação, a Psicologia segue consistindo, nos cursos de Pedagogia pesquisados, em uma das áreas responsáveis pelo embasamento teórico que dará sustentação, legitimidade científica e orientação à atuação docente (Guerra, 2003). E conforme esclarece Larocca (2000), sob a influência de um modelo de "racionalidade técnica", cabe aos Fundamentos da Educação teorizar sobre os fenômenos educativos, enquanto a prática lhe é expurgada, como expressão de uma visão dicotômica entre teoria e prática (p.140).

Ao exercer essa função, a presença da Psicologia na Educação tradicionalmente tem se caracterizado pelo seu caráter essencialmente teórico com predomínio de uma exposição abstrata dos próprios referenciais teóricos psicológicos, que se distanciam da reflexão sobre o cotidiano escolar, as instituições escolares, o processo de escolarização, ou as condições objetivas e concretas que constituem a vida diária escolar protagonizada por diversos participantes, incluindo-se os educadores: "a escola, enquanto instituição social e de ensino, é elemento quase ausente nas ementas, o que leva a pensar numa formação de caráter mais abstrato e pouco integrado ao contexto concreto onde o profissional-professor vai atuar" (Gatti \& Nunes, 2009, p.55). A ausência da realização de estágio nas disciplinas de Psicologia nos quatro cursos investigados reafirma seu caráter eminentemente teórico, ilustrando a "primazia da teoria" desvencilhada da realidade escolar, presente em tais disciplinas (Paini, 2006, p. 83).

O conteúdo ministrado nas disciplinas de Psicologia e a primazia do desenvolvimento e da aprendizagem

O conteúdo ministrado nas disciplinas investigadas é coerente com a estrutura hegemônica presente nos cursos de Pedagogia (Guerra, 2003; Paini, 2006; Gatti, 2009; Gatti \& Nunes, 2009), em que se apresenta inicialmente um panorama histórico que busca dar conta da articulação entre Psicologia e Educação, e em seguida, centra-se na exposição de conceitos referentes ao desenvolvimento humano e à aprendizagem, embasados, fundamentalmente, nas abordagens psicogenética e histórico-cultural, tendo Piaget, Vigotski e Wallon como principais autores de referência. Além disso, foi possível identificar nos cursos pesquisados a presença de uma disciplina articulada às de Psicologia, recorrentemente referida como Educação Inclusiva, que ao abordar a inclusão escolar, envolve a discussão de temas relativos à interface Psicologia e Educação, conforme será mencionado posteriormente. 
Na maioria dos cursos analisados, o panorama histórico inicial é apresentado no primeiro período do curso em uma disciplina que busca introduzir o estudante de Pedagogia nas principais correntes teóricas da Psicologia, situando-a como um campo do conhecimento. Visa-se propiciar uma aproximação dos estudantes à relação entre Psicologia e Educação, por meio da exposição de teorias psicológicas. Para tanto, em algumas instituições são apresentadas abordagens psicológicas como Psicanálise, Behaviorismo e Gestalt, buscando-se uma articulação entre tais teorizações e a Educação. Esses dados confirmam os resultados encontrados por Gatti (2009, p.218), segundo a qual esse panorama abrange referências ao desenvolvimento cognitivo e emocional, incluindo-se a perspectiva Cognitivista, com o intuito de "analisar a contribuição das teorias psicológicas para compreensão do processo de ensino e aprendizagem".

O desenvolvimento humano e a aprendizagem constituem a centralidade das disciplinas de Psicologia dos quatro cursos pesquisados e abrangem a seguinte variedade de configurações: a) há cursos em que desenvolvimento humano e aprendizagem são abordados em uma mesma disciplina voltada para a exposição de conceitos centrais propostos por Piaget, Vigotski e Wallon, buscando-se atentar para implicações educacionais de tais teorizações. Em alguns cursos, incluem-se nessa disciplina proposições de Freinet, bem como de Emília Ferreiro sobre a compreensão da psicogênese da língua escrita; b) em outros cursos, o desenvolvimento e a aprendizagem são abordados exclusivamente com base na teorização de Piaget em uma disciplina, enquanto se dedica outra disciplina para as proposições de Vigotski e Wallon sobre esses processos, explicitando-se o materialismo histórico dialético como base epistemológica de suas teorizações; c) além das teorizações referidas acima, há cursos que apresentam uma disciplina específica sobre o desenvolvimento humano, em que se atenta para cada etapa da vida do homem, desde o período pré-natal à velhice, de modo a se apresentar aspectos cognitivos, afetivos, sociais e motores relativos a cada etapa do desenvolvimento, tendo-se como referência a proposição de autores como Erik Erikson, Freud e Piaget; d) alguns cursos incluem, além do conteúdo mencionado acima, teorias sobre o processo de ensino e aprendizagem, apresentadas em uma disciplina específica, por meio da exposição de modelos epistemológicos que norteiam ações pedagógicas e psicológicas, sendo explicitadas distintas abordagens psicológicas aplicadas à Educação, com a humanista, comportamentalista, psicanalítica e psicogenética, dentre outras, confirmando as abordagens também encontradas por Paini (2006); e) a aprendizagem também é contemplada, em alguns cursos, em uma disciplina sobre o sujeito da aprendizagem, analisado a partir das Neurociências e de referenciais teóricos como
Psicanálise, Construtivismo e Fenomenologia, ou ainda, em uma disciplina que aborda a aprendizagem com base na teorização de Erik Erikson e nas proposições das Neurociências sobre conceitos como memória, atenção, concentração, consciência e pensamento.

Vinculada às disciplinas de Psicologia, nos quatro cursos investigados, há uma disciplina identificada como Educação Inclusiva, em que de modo geral são discutidos a inclusão escolar, os princípios que norteiam a Educação Especial e a Educação Inclusiva, bem como a contextualização histórica de sua implementação no Brasil, os conceitos de normalidade e de deficiência, os processos de exclusão social e cultural e especificidades de distintas necessidades educacionais especiais. Ao fazer referências ao conteúdo nela discutido, os docentes entrevistados fazem alusão a temas relevantes coerentes com contribuições da Psicologia Escolar para a formação de professores, conforme será mencionado no próximo item.

A primazia do desenvolvimento e da aprendizagem como foco central de disciplinas de Psicologia na Pedagogia expressa o pressuposto hegemônico socialmente difundido - reiterado por docentes e estudantes e endossado por políticas públicas educacionais (Levandovski, 2008; Checchia \& Souza, 2016) - de que a principal contribuição da Psicologia para a formação de professores consistiria em fornecer embasamento teórico para a compreensão de processos do desenvolvimento e da aprendizagem, identificados como subsídios que deverão instrumentalizar a prática docente.

No entanto, tal pressuposto tem sido problematizado, pois a pretensão de nortear as orientações práticas educativas, com base em "investigações de cunho psicológico" é discutível diante da inviabilidade de se estabelecer uma transposição direta entre fundamentos teóricos psicológicos e a prática pedagógica, conforme Carvalho (2011) explicita ao afirmar que "essa postulada relação entre concepções teóricas de professores e suas práticas escolares é bastante frágil" (p. 312), pois não é possível "deduzir" de premissas epistemológicas ou teóricas uma prática educativa, já que "os princípios não carregam em si a regra de sua aplicação" (p. 318). Sendo assim, Carvalho enfatiza que os procedimentos de ensino e ação pedagógica apenas poderiam ser compreendidos e encontrar modelos na própria "cultura das instituições escolares" ou no "mundo escolar", que tem sido tradicionalmente menosprezado ou ignorado nas disciplinas de Psicologia, centradas no desenvolvimento e na aprendizagem, em que impera uma concepção abstrata do contexto escolar (p. 317).

Azanha (1998) e Patto (2004) contribuem para tal problematização, ao questionar a premissa radicada na Pedagogia moderna de que o ensino eficaz seria essencialmente decorrente de uma "aplicação competente de um saber metodológico, epistemologicamente funda- 
mentando em outros saberes, principalmente de natureza psicológica" (Patto, 2004, p. 64). Além de enfatizar que derivações práticas de teorias são discutíveis, esses autores ressaltam que tal premissa está alicerçada em uma "relação individual professor-aluno, uma relação à dois abstraída do contexto institucional" (Patto, 2004, p. $65)$, sem considerar que a qualidade do ensino, o sucesso e o fracasso escolar envolvem uma complexidade de elementos implicados em sua produção. Nesse sentido, Azanha (1998, p. 18) esclarece que não se pode buscar resolver o problema da qualidade do ensino por meio da aplicabilidade de teorias do desenvolvimento e da aprendizagem, com um modelo de formação docente em que prevalece "uma visão psicológica do educando" e enfatiza que o exercício docente "só é possível no quadro institucional da escola" e que os desafios da escola contemporânea devem ser objeto de análise na formação de educadores. Encontram-se, portanto, nas proposições desses autores, a crítica ao psicologismo ou psicologização da Educação e a necessidade de se atentar, na formação de professores, para o contexto escolar em sua complexidade.

A primazia do desenvolvimento e da aprendizagem como foco central das disciplinas investigadas nessa pesquisa consiste em uma expressão do psicologismo, que conforme mencionado anteriormente, corresponde ao reducionismo de fenômenos sociais e educacionais ao âmbito individual ou à dimensão subjetiva. Em coerência com o modo hegemônico como a Psicologia se insere historicamente na Pedagogia, essas disciplinas centram no indivíduo a análise de questões na interface Psicologia e Educação, com base em teorizações psicológicas sobre o desenvolvimento do sujeito e a aprendizagem, concebidas como fundamentos teóricos que embasariam a instrumentalização da prática docente. Nesse contexto, evidencia-se a "tendência secular", característica do psicologismo, por meio da qual a Pedagogia assenta-se na Psicologia ancorada nos processos de ensino e aprendizagem, "com o triunfo da racionalidade que instrumenta o progresso técnico" da Educação (Patto, 2004, p. 65).

Deve-se ressaltar que as teorizações no campo da Psicologia do Desenvolvimento e da Aprendizagem são, de fato, relevantes para a formação de professores, no sentido de elucidar especificidades do conhecimento historicamente acumulado sobre esses processos. No entanto, as contribuições da Psicologia para a formação de professores nessas disciplinas não devem se restringir ao âmbito do desenvolvimento e aprendizagem, mas podem abranger discussões proferidas no campo da Psicologia Escolar, que apresentam como foco de análise o processo de escolarização, de modo a atentar para a complexidade implicada no cotidiano escolar e para as relações entre os sujeitos históricos que o constituem. A relevância de tais discussões se intensifica diante da "psicologização dos problemas escolares" (Patto, 2004, p. 66) que tradicionalmente impera nas disciplinas nessa interface que centram a análise das questões escolares no indivíduo, enquanto a escola e o processo de escolarização são abstraídos ou pouco abordados.

O que pudemos identificar nas disciplinas investigadas foi o fato de que embora o conhecimento proferido no campo da Psicologia Escolar sobre o cotidiano escolar e o processo de escolarização não esteja explicitamente indicado nos planos de ensino, os docentes entrevistados anunciam alcances e limites da presença de tais discussões, enfatizando sua relevância para a formação de professores, conforme indicaremos no próximo item.

Alcances e limites da presença de discussões do campo da Psicologia Escolar nos cursos de Pedagogia e suas contribuições para a formação de professores

Ao serem interrogados sobre o processo de escolarização e os elementos relacionais, políticos e institucionais que vêm sendo abordados na Psicologia Escolar, os docentes esclarecem que o conhecimento proferido nesse campo é trabalhado de forma mais explícita na disciplina Psicologia Escolar, oferecida apenas no curso de Psicologia. Os entrevistados que além de serem docentes da Pedagogia, ministram tal disciplina na Psicologia, enfatizam a necessidade e a relevância de se inserir tal conhecimento na formação de professores, argumentando que nessa disciplina são apresentadas a introdução à perspectiva crítica em Psicologia Escolar, o questionamento da culpabilização do indivíduo pelo fracasso escolar e da medicalização da Educação, como expressões do reducionismo de questões educacionais ao âmbito individual, a produção do fracasso escolar, a compreensão da complexidade envolvida no processo de escolarização, as políticas públicas educacionais e o cotidiano escolar, com base em textos de Ana Bock, Marilene Proença R. de Souza, Elenita Tanamachi, Maria Helena Patto, Beatriz de Paula Souza, Maria Aparecida Moysés e Demerval Saviani, dentre outros. Diante disso, consideram que possibilitar a discussão desses temas aos futuros educadores consistiria em uma significativa contribuição da Psicologia Escolar para a sua formação.

No entanto, os docentes afirmam que tal discussão não está explicitamente contemplada na matriz curricular da Pedagogia em uma disciplina específica ou nos planos de ensino das disciplinas de Psicologia e acrescentam que há possibilidade de estabelecer algumas articulações entre esses temas e o conteúdo abordado em tais disciplinas, conforme será indicado posteriormente, mas consideram que tal associação depende da formação, referencial teórico ou trajetória acadêmica e profissional do docente que o aproximem das discussões realizadas nesse campo do conhecimento.

Diante disso, alguns entrevistados consideram que a disciplina Psicologia Escolar deveria ser inserida na 
grade curricular da Pedagogia, ou que o conteúdo programático de ao menos uma disciplina nessa interface deveria contemplar esses temas: "o conteúdo dessa disciplina da Pedagogia deveria se parecer mais com a matéria de Psicologia Escolar que eu dou na Psicologia" (entrevista com o docente João Vitor).

Para justificar tal afirmação, o docente João Vitor argumenta que há um distanciamento entre o conteúdo ministrado nas disciplinas de Psicologia na Pedagogia e a realidade escolar, de modo a não constar em seus planos de ensino a discussão sobre o cotidiano escolar ou os problemas de escolarização, que, por sua vez, consistem no foco de análise da Psicologia Escolar, o que reitera a relevância de se propiciar o conhecimento produzido nesse campo aos futuros educadores.

Tal distanciamento, recorrente nas disciplinas de Psicologia na Pedagogia, bem como a necessidade de nelas se atentar para a instituição e o cotidiano escolar são enfatizados por Larocca (2000), Pereira, Almeida e Azzi (2002), Guerra (2003), Paini (2006) e por Patto (2004, p. 66), segundo a qual falta a essas disciplinas a explicitação da "escola como instituição social portadora de um projeto educativo que tem aspectos filosóficos, históricos, sociais e políticos que os educadores precisam conhecer" e que vêm sendo analisados ao longo do movimento crítico no campo da Psicologia Escolar.

A constituição social e histórica da escola é abordada, segundo João Vitor, nas aulas de Psicologia Escolar ministradas no curso de Psicologia, por meio das quais, segundo esse docente, os estudantes passam a questionar o reducionismo de questões sociais ao âmbito individual, como a culpabilização dos alunos pelo fracasso escolar. No entanto, o docente enfatiza que como as disciplinas na Pedagogia não abordam explicitamente essas questões, sem esse embasamento teórico torna-se menos recorrente a identificação de tais problematizações no discurso destes futuros educadores, enquanto é possível identificar em suas argumentações a reprodução da busca de explicações para os problemas de escolarização ainda centrada em fatores individuais.

Tal constatação é coerente com a identificação do reducionismo do fracasso escolar ao âmbito individual no discurso de estudantes de Pedagogia de outra Universidade, que reproduzem a culpabilização de alunos, famílias ou professores pelo fracasso, o que endossa a relevância de propiciar na formação dos educadores a crítica a esse reducionismo, que vem sendo proferida no campo da Psicologia Escolar (Checchia, 2015).

Percebe-se, portanto, que embora o conhecimento proferido pela Psicologia Escolar esteja presente nos cursos de Psicologia referidos pelos entrevistados, permanece ausente dos planos de ensino das disciplinas da Pedagogia. No entanto, apesar dessa ausência, criticada por alguns docentes, identifica-se a possibilidade de nelas serem abordados temas relevantes referentes ao processo de escolarização, discutidos nesse campo do conhecimento, tais como a medicalização da Educação, a problematização de psicodiagnósticos no contexto escolar, os "problemas de aprendizagem", a estigmatização nas relações escolares, a crítica ao reducionismo de questões sociais ao âmbito individual e à naturalização das questões escolares e a compreensão de sua constituição social e histórica, mencionados a seguir.

De acordo com Rosa e Érica, docentes de uma mesma Universidade, a disciplina Educação Inclusiva é a que mais possibilita a reflexão sobre o processo de escolarização, em articulação com proposições no campo da Psicologia Escolar: ao se abordar a deficiência mental e deficiências no processo de aprendizagem, são problematizadas a realização de psicodiagnósticos e a medicalização da Educação, proferindo-se críticas à estigmatização e patologização da queixa escolar. Um dos textos básicos utilizados na bibliografia aborda especificamente a questão do psicodiagnóstico e apresenta uma perspectiva crítica de avaliação e de intervenção do psicólogo voltado para questões educacionais, de modo a propiciar tal discussão.

Ao longo das disciplinas de Psicologia na Pedagogia, Rosa e Érica buscam questionar a estigmatização dos alunos no contexto escolar, propiciar a crítica à concepção de "problemas de aprendizagem" cuja origem é tradicionalmente associada a fatores centrados no indivíduo e à concepção inatista de inteligência, como expressão do reducionismo de questões sociais ao âmbito individual. As docentes enfatizam a relevância de se propiciar tais questionamentos aos estudantes de Pedagogia, que não terão a oportunidade de assistir à disciplina Psicologia Escolar, oferecida na Psicologia, em que esses temas são aprofundados; diante disso, evidenciam e se ressentem da ausência desse campo do conhecimento na formação de professores.

Narcisa, docente de outra Universidade, também ressalta a relevância de se problematizar o reducionismo ao âmbito individual. Segundo ela, esse questionamento pode ser realizado na primeira disciplina oferecida na interface Psicologia e Educação, ao se discutir um texto de José Libâneo em que autor critica a psicologização na Educação e por meio do qual é possível refletir sobre a atribuição de diagnósticos e rótulos aos alunos ou expressões de reducionismos como a medicalização da Educação, de modo a resgatar a dimensão social e histórica dos fenômenos analisados. A necessidade de reflexão sobre esses rótulos também é enfatizada pela docente Fátima, ao fazer alusão à importância de se questionar os rótulos que são atribuídos aos alunos tidos como "portadores de dificuldades" ou com "distúrbios de aprendizagem" (entrevista com Fátima).

Por fim, outra docente, Sofia, destaca que a partir dos anos 1990, as disciplinas de Psicologia no curso de 
Pedagogia em que leciona passaram a visar à formação de um pedagogo crítico, no sentido de propiciar a compreensão de que o homem e os fenômenos educativos se constituem social e historicamente, em contraposição à sua naturalização. Sendo assim, esclarece que a concepção de homem (e de alunos no contexto escolar, mais especificamente), como um sujeito biopsicossocial, embasa tais disciplinas, sendo nelas abordada.

Esses temas referidos pelos docentes não consistem propriamente em conteúdos programáticos das disciplinas como objetos de estudo fundamentados teoricamente nos textos que constam na bibliografia básica dos planos de ensino ou em textos específicos que os abordem, mas sim, segundo os entrevistados, surgem da discussão decorrente da exposição do conteúdo ministrado ou do relato de experiência dos estudantes.

A relevância de abordar esses temas também é ressaltada por docentes dessas disciplinas da Pedagogia (e demais Licenciaturas) de uma Universidade pública do estado de São Paulo, que incluem em seu conteúdo programático o conhecimento proferido no campo da Psicologia Escolar que envolve a reflexão sobre a produção do fracasso escolar e seu reducionismo ao âmbito individual, a compreensão de elementos sociais, políticos e institucionais implicados na escolarização, a problematização da queixa escolar (e dos problemas de escolarização) e sua patologização, as relações intersubjetivas que constituem o cotidiano escolar e os estereótipos que o atravessam (Checchia, 2015).

As discussões relativas a esses temas, realizadas ao longo do movimento crítico na Psicologia Escolar, podem contribuir para a formação de professores ao propiciar a compreensão da complexidade envolvida no processo de escolarização, o questionamento da legitimação científica de preconceitos que atravessam o cotidiano escolar e a explicitação do caráter ideológico de teorizações naturalizantes e reducionistas que produzem marcas e efeitos na vida escolar dos sujeitos e por meio das quais alunos, suas famílias ou professores são culpabilizados pelo fracasso escolar. Embora não estejam efetivamente presentes no plano de ensino das disciplinas investigadas, a necessidade e a relevância de se inserir tal reflexão na Pedagogia são endossadas por docentes que buscam introduzi-la aos estudantes.

Concepção dos docentes sobre as contribuições das disciplinas de Psicologia ministradas na Pedagogia

Os entrevistados afirmam que tais disciplinas deveriam propiciar aos futuros educadores um olhar crítico que embasa a compreensão da constituição social e histórica do sujeito, da sociedade e dos fenômenos educativos, em oposição à sua naturalização, de modo a situar os problemas de escolarização no contexto social e histórico. Alguns docentes enfatizam que a principal contribuição de tais disciplinas para a formação dos professores deveria consistir em propiciar a discussão sobre o fracasso escolar e os temas referidos no item anterior, com base em uma perspectiva crítica em Psicologia Escolar; além disso, consideram que se deveria possibilitar a reflexão sobre o modo como a Psicologia foi influenciando historicamente a Educação e como a Psicologia é concebida nas escolas na conjuntura atual, questionando a influência da medicalização, bem como oferecer um embasamento teórico para o enfrentamento de problemas de escolarização e para que pedagogos e psicólogos se entendam no diálogo em relação às questões escolares.

Evidencia-se, portanto, no discurso dos entrevistados, tanto uma ruptura em relação à concepção hegemônica de que a principal contribuição dessas disciplinas deveria ser a transmissão de teorizações do desenvolvimento e da aprendizagem como instrumentalização da prática docente, quanto a necessidade de que tais disciplinas ofereçam contribuições para a formação de professores por meio de conhecimentos proferidos no campo da Psicologia Escolar.

\section{CONSIDERAÇÕES FINAIS}

Diante da primazia do desenvolvimento e da aprendizagem nas disciplinas investigadas e de uma presença ainda incipiente de temas relativos ao processo de escolarização abordados no campo da Psicologia Escolar, que não constam efetivamente em seus planos de ensino, mas podem se tornar objeto de discussão a partir da problematização de questões que atravessam o cotidiano escolar, mencionadas pelos entrevistados, alguns docentes enfatizam a necessidade de inserção do conhecimento produzido nessa área em seu conteúdo programático e buscam introduzi-lo aos estudantes, visando favorecer a crítica à naturalização e ao reducionismo de questões escolares e sociais ao âmbito individual, bem como a compreensão da constituição social e histórica do homem e dos fenômenos na interface Psicologia e Educação.

É importante enfatizar que como esses temas referidos pelos entrevistados não estão presentes nos planos de ensino das disciplinas de Psicologia na Pedagogia, a inserção da discussão sobre essas temáticas referentes ao processo de escolarização, alicerçadas em uma perspectiva crítica no campo da Psicologia Escolar, na formação de professores, fica condicionada à iniciativa individual de docentes que tenham tido em sua trajetória acadêmica ou profissional o acesso e a apropriação de uma concepção social e histórica desses fenômenos. Esse fato endossa a necessidade de que o conhecimento acumulado ao longo do movimento crítico em Psicologia Escolar passe a ser oficialmente contemplado nos planos de ensino de disciplinas de Psicologia nos cursos de Pedagogia.

As contribuições da Psicologia Escolar para a for- 
mação de professores, com base em uma perspectiva crítica, estão alicerçadas em um compromisso ético e político que envolve a luta pela transformação social, pela educação pública de qualidade e pela humanização do homem e das relações escolares; sendo assim, abrangem a denúncia de mecanismos de exclusão, opressão e humilhação, subjacentes ao modo de produção capitalista, que atravessam as relações escolares e são endossados por teorizações psicológicas naturalizantes (Checchia, 2015). A reflexão sobre os temas mencionados pelos entrevistados à luz do conhecimento proferido nesse campo, propicia aos futuros educadores, protagonistas da vida diária escolar, o questionamento da patologização, estigmatização e desumanização das relações escolares, que trazem implicações para a vida diária escolar e com as quais esses profissionais podem passar a não compactuar.

Essa questão é enfatizada por Patto (2004, p. 70), que se refere à relevância de se propiciar aos educadores uma reflexão sobre a dimensão ética e política da Educação e argumenta que a Psicologia pode oferecer uma importante contribuição ao processo de mudança de concepções dos educadores ao problematizar "crenças e valores arraigados (alguns petrificados) no imaginário social" e acrescenta que nessa formação, "as teorias críticas devem ser apropriadas com rigor, para que se possam pensar as questões postas a todos pela ação que se quer transformadora das circunstâncias e dos homens".

Diante das considerações apresentadas até então, evidencia-se, portanto, a relevância de que tais reflexões passem a compor efetivamente o plano de ensino de disciplinas de Psicologia nos cursos de Pedagogia, de modo a propiciar a ruptura com a hegemônica primazia do indivíduo, que historicamente as constitui, e a contribuir para a formação crítica dos educadores, alicerçada na análise do cotidiano escolar e na problematização da naturalização e de reducionismos na interface Psicologia e Educação, que não devem ser legitimados ou reproduzidos por docentes dessas disciplinas ou pelos estudantes, ao longo de sua formação e atuação como profissionais da Educação.

\section{REFERÊNCIAS}

Almeida, M. I.; Pimenta, S. G.; Fusari, J. C. F. (2016). Inserção profissional de licenciados egressos da Universidade de São Paulo: processos de construção de identidades, socialização profissional e profissionalização docente. Relatório Final da Pesquisa à Faculdade de Educação da Universidade de São Paulo. Processo no 2014/00217-2.

André, M. E. D. A. de. (1995). Etnografia da prática escolar. São Paulo: Papirus.

André, M. E. D. A. de. (1983). Texto, contexto e significados: algumas questões na análise de dados qualitativos. Cadernos de Pesquisa, (45), 66-71.
Antunes, M. A. M. (2003). Psicologia e educação no Brasil: um olhar histórico-crítico. In: M. E. M. Meira; M. A. M. Antunes (Eds.), Psicologia escolar: teorias críticas (pp.139-168). São Paulo, SP: Casa do Psicólogo.

Azanha, J. M. P. (1998). Proposta pedagógica e autonomia da escola. Cadernos de História e Filosofia da Educação, II(4), pp. 11-21.

Carvalho, J. S. F. de. (2011). A teoria na prática é outra? Considerações sobre as relações entre teoria e prática em discursos educacionais. Revista Brasileira de Educação, 16(47), 307-320.

Checchia, A. K. A. (2015). Contribuições da Psicologia Escolar para a formação de professores: um estudo sobre a disciplina Psicologia da Educação nas Licenciaturas (Tese de Doutorado). Universidade de São Paulo, São Paulo - SP. Recuperado de https://www.teses.usp.br/teses/ disponiveis/47/47131/tde-07082015-114724/pt-br.php

Checchia, A. K. A.; Souza, M. P. R. (2016) A disciplina Psicologia da Educação na formação de professores: reflexões a partir da Psicologia Educacional e Escolar. In: H. R. Campos; M. P. R. de Souza; M. G. D. Facci (Eds.), Psicologia e políticas educacionais (pp. 295-323). Rio Grande do Norte: EDUFRN.

Denzin, N. K.; Lincoln, Y. G. (2006). Introdução-A disciplina e a prática da pesquisa qualitativa. In: N. K. Denzin; Y. S. Lincoln (Eds.), Planejamento da pesquisa qualitativa - Teorias $e$ abordagens (pp. 15-41). Porto Alegre, RS: Artmed.

Gatti, B. (2009). Psicologia da educação e formação de professores. Trabalho Encomendado - GT Psicologia da Educação, 32ª Reunião Anual da ANPED. Mimeo.

Gatti, B. (2010). Psicologia da educação: conceitos, sentidos e contribuições. Psicologia da Educação, (31), 7-22. Recuperado de http://pepsic.bvsalud.org/scielo. php?script=sci_arttext\&pid=S1414-69752010000200002

Gatti, B.; Nunes, M. (Eds). (2009). Formação de professores para o ensino fundamental: estudo de currículos das licenciaturas em pedagogia, língua portuguesa, matemática e ciências biológicas. São Paulo, SP: FCC/DPE.

Guerra, C. (2003). O ensino de psicologia na formação inicial de professores: constituição de conhecimentos sobre aprendizagem e desenvolvimento por estudantes de licenciaturas (Tese de Doutorado). Universidade Estadual de Campinas, Campinas - SP. Recuperado de http:// repositorio.unicamp.br/jspui/handle/REPOSIP/253639

Instituto Nacional de Estudos e Pesquisas Educacionais Anísio Teixeira [INEP]. Sinopse Estatística da Educação Superior 2016. Brasília: INEP, 2017. Recuperado em 10 de março de 2018, de http://portal.inep.gov.br/web/guest/sinopsesestatisticas-da-educacao-superior.

Larocca, P. (2000). O ensino de psicologia da educação sob o olhar de licenciados e licenciandos. In: R. Azzi; S. H. Batista; A. M. Sadalla (Eds.), Formação de professores: discutindo o ensino de psicologia (pp. 119-144). Campinas, SP: Editora Alínea.

Levandovski, A. R. (2008). Contribuição da disciplina Psicologia da Educação para a prática docente no Ensino Fundamental 
I- um estudo por meio da metodologia da problematização (Dissertação de Mestrado). Universidade Estatual de Londrina, Londrina - PR. Recuperado de https://bdtd. ibict.br/vufind/Record/UEL_085a551adbbfe9dd48b1d6 $053 \mathrm{a} 032157$

Libâneo, J. C. (2012). Psicologia educacional: uma avaliação crítica. In: S.T. M. Lane; W. Codo (Eds.), Psicologia social: o homem em seu movimento (14a ed., pp. 154-180). São Paulo, SP: Ed. Brasilense.

Paini, L. (2006). Psicologia educacional: a vez e a voz dos acadêmicos de pedagogia das universidades estaduais do Paraná (Tese de Doutorado). Universidade de São Paulo, São Paulo - SP. Recuperado de http://bdtd.ibict.br/vufind/ Record/USP_a31287ee34fd4d3f21f1e27246ca2d82

Patto, M. H. S. (Ed.). (1997). Introdução à psicologia escolar (3a ed.). São Paulo: Casa do Psicólogo.

Patto, M. H. S. (2004). Formação de professores: o lugar das humanidades. In: R. Barbosa (Ed.), Trajetórias e perspectivas da formação de educadores (pp. 61-78). São
Paulo: Editora UNESP.

Patto, M. H. S. (2015). A produção do fracasso escolar: histórias de submissão e rebeldia. São Paulo: Intermeios.

Pereira, M. A. L.; Almeida, P. C. A. de; Azzi, R. G. (2002). A dimensão teórico-prática da psicologia educacional na formação de professores: a metodologia da problematização como desencadeadora da articulação entre teoria e prática. In: R. Azzi; A. M. Sadalla (Eds.), Psicologia e formação docente: desafios e conversas (pp. 185-211). São Paulo, SP: Casa do Psicólogo.

Queiroz, M. I. P. de. (1983). Variações sobre a técnica de gravador no registro da informação viva. São Paulo: CERU e FFLCH/USP.

Souza, M. P. R. de (2010). Retornando à patologia para justificar a não aprendizagem escolar: a medicalização e o diagnóstico de transtornos de aprendizagem em tempos de neoliberalismo. In: CRP/SP; GIQE (Eds.), Medicalização de crianças e adolescentes: conflitos silenciados pela redução de questões sociais a doenças de indivíduos (pp. 57-67). São Paulo, SP: Casa do Psicólogo.

Recebido: 30 de julho de 2019 Aprovado: 12 de agosto de 2020 